\title{
Autologous rectus fascia sling for post-vesicovaginal fistula repair stress incontinence: case series from a Nigerian experience
}

\author{
Olatunji Okikiola Lawal', Sadiya Nasir², Oluwasomidoyin Olukemi Bello ${ }^{1 *}$, Rukiyat Adeola Abdus-salam', \\ Imran Oludare Morhason-Bello', A. M. El-ladan² and Oladosu Akanbi Ojengbede ${ }^{3}$
}

\begin{abstract}
Background: Successful outcome of a urinary fistula repair involves a successful closure of the fistula without residual incontinence. However, a few women have post-repair stress urinary incontinence despite closure of the fistula, which requires special surgical technique to achieve total continence.

Case presentation: Four women with post-vesicovaginal fistula repair residual incontinence were selected for sling operation using autologous rectus fascia in a low resource setting. Their ages ranged between 20 and 30 years. None had a fistulous opening on vaginal examination and dye test. Two patients had one previous attempt at repair of post-repair stress incontinence, while the others had two and three attempts, respectively, without success. The patients had none to mild vaginal adhesion. Following the procedure, they were followed up for 6 months and they remained continent of urine.

Conclusion: All patients achieved total urinary continence following autologous rectus fascia slings with minimal complications. This demonstrates the possibility of achieving a successful outcome despite lack of modern equipment for diagnosis and follow-up, a typical problem of low-income country like Nigeria.
\end{abstract}

Keywords: Vesicovaginal fistula, Post-repair urinary incontinence, Autologous sling

\section{Background}

Residual urinary incontinence following vesicovaginal fistula (VVF) closure constitutes a dilemma for both the patient and attending surgeon [1]. Residual urinary incontinence complicates VVF repair when it involves the sphincteric region of the bladder/bladder neck, large and severe vaginal fibrosis [2-5]. The repair of VVF that involved the bladder neck with or without its sphincter

\footnotetext{
*Correspondence: bellodoyin@yahoo.com

${ }^{1}$ Genitourinary/Urogynaecology Unit, Department of Obstetrics and Gynaecology, Faculty of Clinical Sciences, College of Medicine, University of Ibadan, University College Hospital, PMB 5116, Ibadan, Oyo State, Nigeria

Full list of author information is available at the end of the article
}

sometimes leads to obliteration of the angulation of the bladder neck and subsequent leakage of urine. The resultant urinary incontinence from such VVF repair is due to loss of intraurethral pressure. Although the exact prevalence of post-VVF repair stress incontinence is not known, evidence suggests that residual urinary incontinence including post-repair stress incontinence ranged between 8 and 13\% [6, 7]. Post-VVF repair stress incontinence could present mildly in a woman with supposedly closed fistula when there is increase in intraabdominal pressure during coughing, laughing, or lifting a heavy object or bearing down. However, in severe cases, there could be leakage of urine when walking or standing up as if there is still an existing fistula [4]. 
Studies had shown that urinary incontinence could result in significant psychosocial challenges and mental health issues like anxiety and depression [8]. Ojengbede et al. [9] further showed that the risk of mental ill health was higher among women with failed repair which could be due to post-repair stress incontinence. Unlike the classical stress incontinence that is usually managed with dissection and anterior wall repair or TOT or TVT with good outcome, urinary stress incontinence following successful closure of VVF is usually associated with guarded outcome due to fibrosis from previous surgery $[1,3,4]$.

There are different surgical techniques for the treatment of post-repair incontinence. The functional outcome of these techniques depends on the degree of damage to the pelvic floor, bladder and urethral closure mechanism, and degree of urethral loss. The management of post-repair incontinence may be non-surgical or surgical. The non-surgical technique involves conservative management, employing the use of physiotherapy [including pelvic floor exercises and bladder training]. Pharmacological agents such as anticholinergic drugs are also useful in treating selected cases of mild stress incontinence. Urethral plugs are sometimes used with positive outcome $[1,10]$.

The specific surgical procedures such as colposuspension and urethral augmentation have also been used to manage post-repair stress incontinence with some degree of success $[11,12]$. Other techniques include the use of gracilis, bulbocavernosus, and levator ani muscles to augment and reinforce the urethral in order to achieve continence [13]. The use of autologous slings is now gaining popularity as a unique technique to correct the bladder neck angulation. The tissue that is used for the sling is commonly harvested from the rectus sheath. This procedure has been associated with good success rate even at facilities where modern urological equipment such as urodynamic is not available. We present a case series of carefully selected patients with clinical evidence of postVVF repair stress incontinence managed in Nigerian Obstetric Fistula facility.

\subsection{Case presentation}

All the patients selected for this case series were managed at the Baba-Rugar National Obstetric Fistula Centre, Kastina, Nigeria. Their surgeries were performed between November 11-18, 2018, and they were followed up for 6 months. These were women who presented with post-repair urinary incontinence following successful closure of VVF fistula during a fistula camp. The main complaint was leakage of urine when standing, but they were all continent of urine when lying down. None of the women had lower abdominal pain, dysuria, and haematuria. The initial surgeries were done at different time intervals ranging between 1 and 2 years, and closure of fistula defect was confirmed with an examination under anaesthesia and dye test.

A pre-operative evaluation was performed for all the patients. The clinical parameters extracted from the medical records include type of previous fistula, number of repairs, degree of scarring, vaginal length, vaginoplasty, urethral length, previous continence procedure, and interval between surgery and incontinence. Four of the women were selected for the procedure.

The inclusion criteria for this case series included the absence of previous abdominal surgery, absence of severe vaginal scarring, urethra length of more than $3 \mathrm{~cm}$, vaginal length of more than $6 \mathrm{~cm}$, and bladder volume of more than $150 \mathrm{mls}$ (Table 1). All patients had urinalysis and urine for microscopy, culture and sensitivity, and full blood count. Stress incontinence was entirely diagnosed by history and clinical examination due to lack of urodynamic machine. Informed consent was obtained from individual patient. Each of the selected patients had the procedure done after a satisfactory pre-operative evaluation. All patients were followed up for 6 months.

\subsection{Description of the surgical procedure}

The surgical procedure was performed in dorsal lithotomy position under spinal anaesthesia using an abdominal and vaginal approach. The abdomen and perineal operation sites were prepared and draped providing access to the vagina and lower abdomen. Peri-operative antibiotics were administered, and the bladder was emptied with metal catheter. A 5-cm-long transverse incision was made on the anterior abdominal wall, $2 \mathrm{~cm}$ above the suprapubic region ( 3 to $5 \mathrm{~cm}$ above the symphysis pubis) and dissected to the rectus sheath. A $10-\mathrm{cm}$ by $2-\mathrm{cm}$ strip of rectus sheath was harvested [Fig. 1]. Each end of the strip was secured with a non-absorbable suture-nylon $2 / 0$ stitches. The two ends of the harvested sheath were left with stay sutures. The fatty tissue on the rectus sheath was cleaned and stored in a warm saline solution until it was ready to use.

Next, the retropubic space was opened through the abdominal incision until the endopelvic fascia was visible. The vaginal dissection was done through a $2-3-\mathrm{cm}$ midline incision on the vaginal mucosa overlying the urethral

\section{Table 1 Eligibility criteria}

Selection criteria for rectus sheath autologous sling

Absence of previous abdominal surgery

Absence of severe vaginal scarring

Urethra length $\geq 3 \mathrm{~cm}$

Vaginal length $\geq 6 \mathrm{~cm}$

Bladder volume $\geq 150 \mathrm{mls}$ 

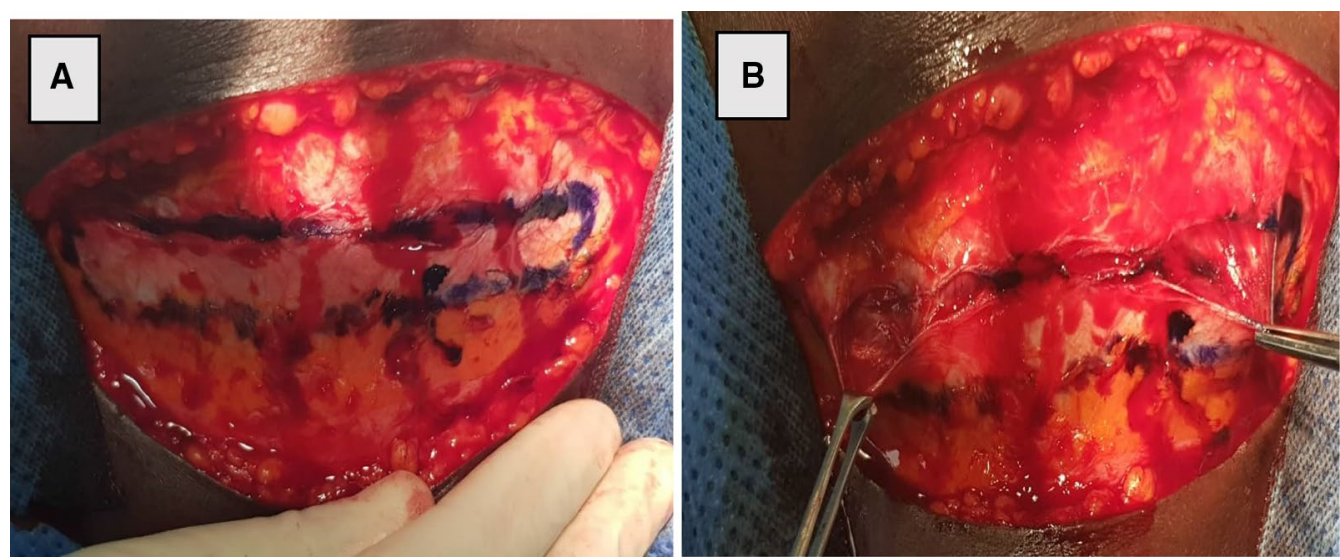

Fig. 1 a Marked rectus sheath $(10 \mathrm{~cm}$ by $2 \mathrm{~cm}$ ). b Harvesting/raising a flap of the rectus sheath

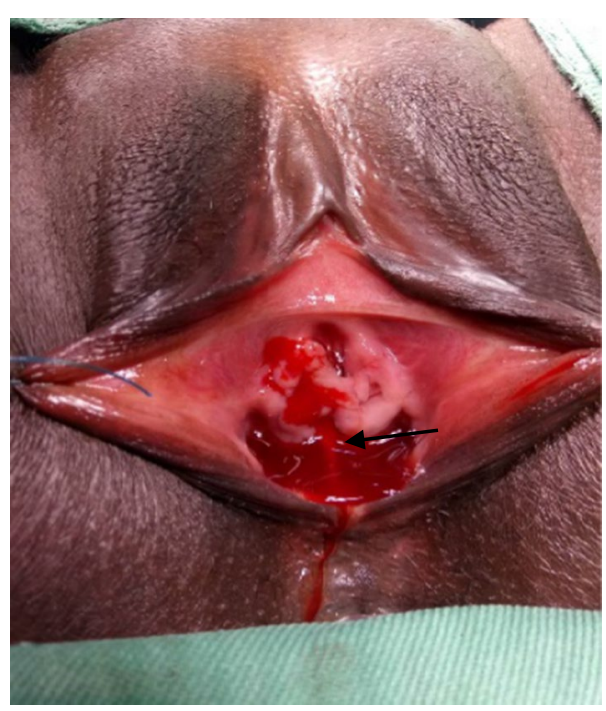

Fig. 2 Vagina dissection with a 2-3-cm midline incision on the vaginal mucosa overlying the urethral and bladder neck (arrow)

and bladder neck [Fig. 2]. A tunnel was created superficial to the pubo-cervical fascia using sharp dissection in a plane towards the patient' ipsilateral shoulder until the endopelvic fascia was perforated. The long-curved clamp was carefully passed downwards, through the endopelvic fascia, using the vagina finger as a guide to protect the urethral and bladder. The finger meets the clamp as it perforates the endopelvic fascia. The stay suture attached to the end of the harvested rectus sheath was pulled through the abdominal incision on both sides, while the vaginal assistant surgeon guides the fascial sling to come to lie over the mid-urethral [Fig. 3]. Two small incisions were made in the lower rectus sheath and the suture ends pulled through. A urethral catheter was passed, and the slings were adjusted from the abdomen to ensure that it was tension-free and there was no leakage of urine before the two ends were tied [Fig. 4]. The rectus sheath and skin were closed. The vaginal mucosa was closed over the sling, and a vaginal pack left in situ for $12 \mathrm{~h}$. The bladder was maintained on continuous drainage for $24 \mathrm{~h}$, and the patients were asked to void. The post-void residual urine volume was measured with catheter drainage.

\section{Results}

Four women were managed, and their ages ranged between 20 and 30 years as presented in Table 2. None had a fistulous opening on vaginal examination and dye test. As presented in Table 3, two patients had one previous attempt at repair of post-repair stress incontinence while the others had two and three attempts, respectively, without success. The patients had none to mild vaginal adhesion, and the bladder length ranged from $9 \mathrm{~cm}$ to $11 \mathrm{~cm}$. The procedure was successful in all the patients. At 1-month follow-up, urinary stress test was negative with no urinary leakage on coughing or bearing down in all the patients. All the four patients were followed up for 6 months, and they remained continent of urine. Three of the patients had resumed sexual intercourse at 6-month follow-up and reported to be continent of urine.

\section{Discussion}

The four cases presented highlighted the role of using autologous rectus sheath sling in the management of stress incontinence following successful VVF repair. These women had minimal vagina scarring and adequate urethral length with no residual fistula at presentation. Despite multiple attempts of VVF repairs in two patients, the four patients had successful sling 

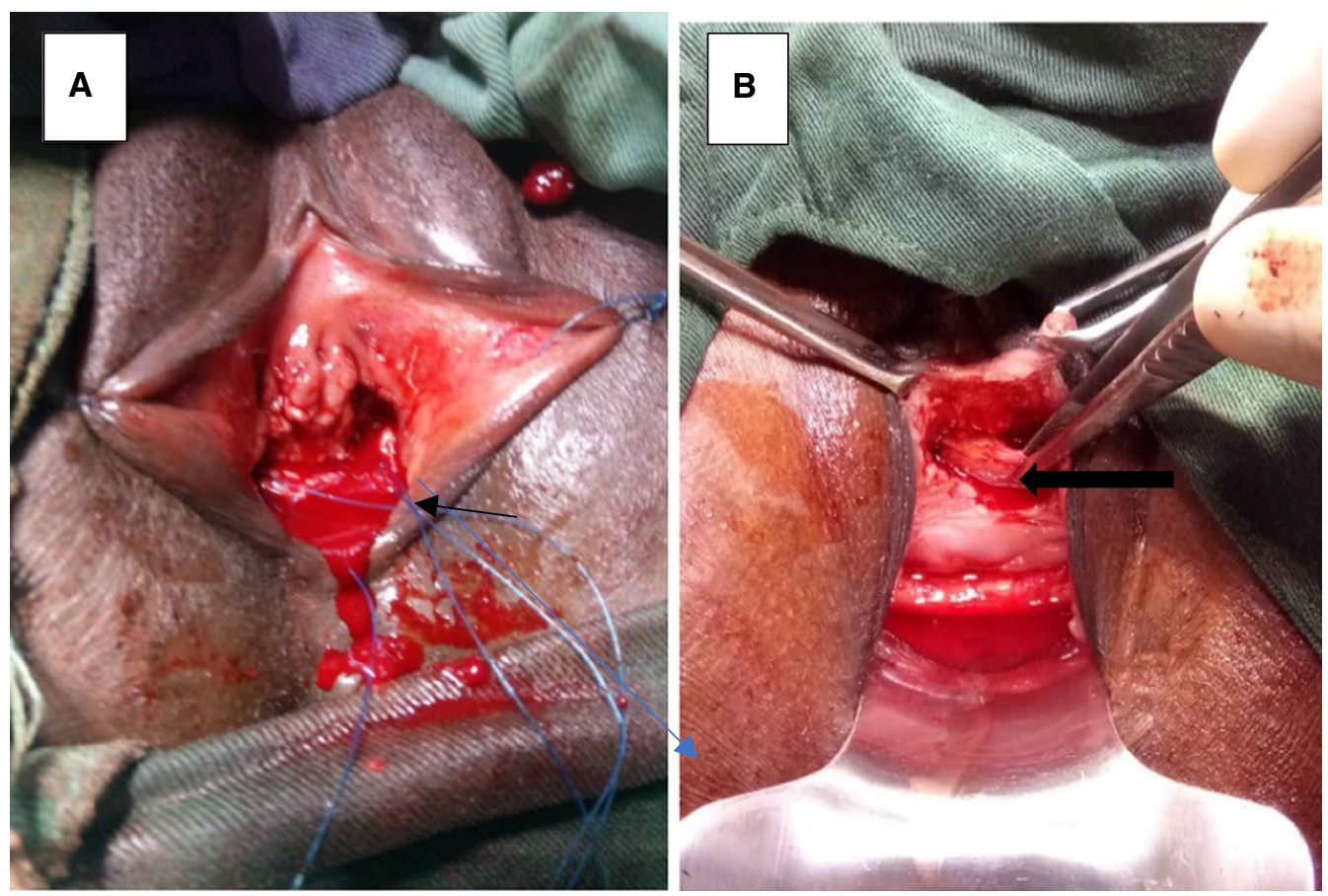

Fig. 3 a Stay suture attached to the end of the harvested rectus sheath (small arrow). b Vaginal assistant surgeon guides the fascial sling to come to lie over the mid-urethral (large arrow)

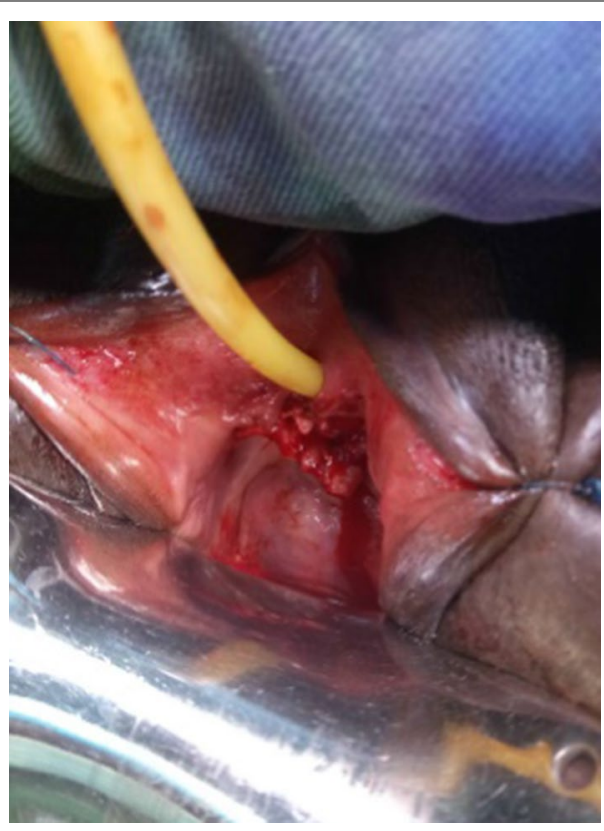

Fig. 4 Foleys urethral catheter inserted with no urine leakage after the slings were adjusted from the abdomen before the two ends were tied operation done with no clinical evidence of stress incontinence at 6 months after the procedure. A study in Tanzania showed that history of vaginal scarring, involvement of the urethra, and number of previous VVF repair were associated with poor outcome [4].

The sling creates a platform for urethral support allowing compression from above and below during increase in intraabdominal pressure [14]. Increased urethral pressure is believed to prevent incontinence; however, the risk of excessive compression is a known complication resulting in voiding dysfunctions. Only one of our patients had voiding dysfunction which resolved following intermittent self-catheterization. Other known complications are bladder injury, infection, wound seroma, vaginal erosion, and failed procedure $[15,16]$. The most common site to fix the sling is the rectus sheath. The cooper's ligament and pubic bone are alternative solid points of fixation [14]. The site of fixation of the sling has not been shown to affect failure rates. Taafesse et al. [17] described the use of retropubic urethrolysis and sling operation in 56 patients with overall success rate of $73.2 \%$. A larger study that involved 140 women treated with sling procedure for residual incontinence showed the same success rate regardless of the material used. However, women with synthetic sling were at a higher risk of erosion and iatrogenic fistula [18]. 
Table 2 Socio-demographic characteristics of the patients

\begin{tabular}{|c|c|c|c|c|c|c|}
\hline Patient & Age (years) & Marital status & Level of education & $\begin{array}{l}\text { Number of previous } \\
\text { deliveries }\end{array}$ & $\begin{array}{l}\text { No of children } \\
\text { alive }\end{array}$ & $\begin{array}{l}\text { Duration } \\
\text { of complaint } \\
\text { (years) }\end{array}$ \\
\hline 1 & 30 & Divorced & None & 2 & 0 & 6 \\
\hline 2 & 21 & Married & Primary & 1 & 0 & 0.5 \\
\hline 3 & 24 & Married & None & 4 & 3 & 1 \\
\hline 4 & 30 & Married & None & 6 & 1 & 2 \\
\hline
\end{tabular}

Table 3 Clinical and fistula characteristics

\begin{tabular}{|c|c|c|c|c|}
\hline \multirow[t]{2}{*}{ Variables } & \multicolumn{4}{|l|}{ Patients } \\
\hline & 1 & 2 & 3 & 4 \\
\hline Type of previous fistula & $\begin{array}{l}\text { Large (involve blad- } \\
\text { der neck) }\end{array}$ & Proximal urethral loss & Proximal urethral loss & $\begin{array}{l}\text { Multiple fistula (mid- } \\
\text { vaginal, proximal } \\
\text { urethra loss) }\end{array}$ \\
\hline Number of fistula repairs & 1 & 2 & 2 & 1 \\
\hline Degree of scarring & Mild & None & None & Mild \\
\hline Vaginal length (cm) & 6.2 & 9 & 9 & 6.5 \\
\hline Previous vaginoplasty & $\mathrm{Nil}$ & $\mathrm{Nil}$ & Nil & Nil \\
\hline Urethra length & 3 & 3.2 & 3.2 & 3.5 \\
\hline Previous incontinence procedure & Yes & Yes & Yes & Yes \\
\hline Outcome & Successful & Successful & *Successful & Successful \\
\hline
\end{tabular}

*Patient had significant post-residual volume after voiding. She practiced self-catheterization for 2 weeks after which voiding normalized

Autologous sling procedure is cheap, easy to perform, and has lesser episode of complication unlike the TOT and TVT procedures that are performed with mesh. Apart from the risk of complication associated with TVT and TOT, they are also more expensive than autologous sling procedure. In addition, there is growing body of evidence that mesh could erode into the bladder or urethra and sometimes trap the nerve endings causing intractable pain. These unpleasant experiences are making many providers and professional organization to seek alternative surgical procedures to manage stress incontinence. Hamlin et al. used gracilis muscle and augmentation of urethral on 35 women with residual stress incontinence with a success rate of 70\% [19]. Browning described a technique that involved narrowing of the bladder neck, urethral lengthening, and reinforcement with pubococcygeus muscle. This technique is associated with limited complications and good results [12].

This case series provided a ray of hope to many fistula patients whose defects had been closed but remained with stress incontinence. We demonstrated the possibility of achieving a successful outcome despite lack of modern equipment for diagnosis and follow-up, a typical problem of low-income country. The team has commenced a multicenter trial of using autologous surgical technique for eligible patient with stress incontinence after a success VVF repair in Nigeria. We hope to share further evidence in the nearest future.

In conclusion, these case series demonstrate the possibility of achieving a successful outcome using autologous rectus fascia slings with minimal complications among fistula patients with post-repair stress incontinence. This can be adopted in a low-income country where there is limited modern equipment like urodynamic machine after detailed evaluation and patient selection.

\section{Abbreviations}

WF: vesicovaginal fistula; TOT: Trans-obturator Tension-free Tape; TVT: Transvaginal Tension-free Tape.

\section{Acknowledgements}

Not applicable.

\section{Authors' contribution}

OL was involved in design of the study, data acquisition, analysis and interpretation, drafted the manuscript, and substantively revised it. SN was involved in data acquisition, analysis and interpretation and substantively revised the manuscript. OB was involved in data acquisition, analysis and interpretation and substantively revised the manuscript. RA was involved in data acquisition, analysis and interpretation and substantively revised the manuscript. IM was involved in design of the study, data analysis with interpretation and substantively revised the manuscript. AE was involved in data acquisition, analysis and interpretation and substantively revised the manuscript. OO was involved in design of the study, data acquisition, analysis and interpretation and substantively revised the manuscript. All authors approved the manuscript in the present format. 


\section{Funding}

This study was not funded by any organization.

\section{Availability of data and materials}

All data generated or analysed during this study are included in this published article.

\section{Ethical approval and consent to participate}

The approval for the study was obtained from the state ethics committee and was given approval number AD 13/479/902B. Written consent was obtained from all the participants.

\section{Consent for publication}

Written consent for publication was obtained.

\section{Competing interests}

The authors declare that they have no competing interests.

\section{Author details}

${ }^{1}$ Genitourinary/Urogynaecology Unit, Department of Obstetrics and Gynaecology, Faculty of Clinical Sciences, College of Medicine, University of Ibadan, University College Hospital, PMB 5116, Ibadan, Oyo State, Nigeria. ${ }^{2}$ National Obstetric Fistula Centre, Babbar-Ruga, Katsina, Nigeria. ${ }^{3}$ Centre for Population and Reproductive Health, Ibadan, Nigeria.

Received: 27 February 2020 Accepted: 10 August 2020

Published online: 30 October 2020

\section{References}

1. Breen M, Ingber M (2019) Controversies in the management of vesicovaginal fistula. Best Pract Res Clin Obstet Gynaecol 54:61-72

2. Bengtson AM, Kopp D, Tang JH, Chipungu E, Moyo M, Wilkinson J (2016) Identifying patients with vesicovaginal fistula at high risk of urinary incontinence after surgery. Obstet Gynecol 128(5):945-953

3. Goh JT, Browning A, Berhan B, Chang A (2008) Predicting the risk of failure of closure of obstetric fistula and residual urinary incontinence using a classification system. Int Urogynecol J Pelvic Floor Dysfunct 19:1659-1662

4. Browning A (2006) Risk factors for developing residual urinary incontinence after obstetric fistula repair. BJOG 113(4):482-485

5. Rajaian S, Pragatheeswarane M, Panda A (2019) Vesicovaginal fistula: review and recent trends. Indian J Urol 35(4):250-258

6. Kelly l, Kwast B (1993) Epidemiological study of vesicovaginal fistulas in Ethiopia. Int J Urogynecol 4:278-281
7. Browning A (2004) Prevention of residual urinary incontinence following successful repair of obstetric vesico-vaginal fistula using a fibromuscular sling. BJOG 111:357-361

8. El Ayadi AM, Barageine J, Korn A, Kakaire O, Turan J, Obore S et al (2019) Trajectories of women's physical and psychosocial health following obstetric fistula repair in Uganda: a longitudinal study. Trop Med Int Health 24(1):53-64

9. Ojengbede OA, Baba Y, Morhason-Bello IO, Armah M, Dimiti A, Buwa D, Kariom M (2014) Group psychological therapy in obstetric fistula care: a complementary recipe for the accompanying mental ill health morbidities? Afr J Reprod Health 18(1):155-159

10. Brook G, Tessema AB (2013) Obstetric fistula: the use of urethral plugs for the management of persistent urinary incontinence following successful repair. Int Urogynecol J 24:479-484

11. Waaldijk K (1994) Step by step surgery of vesicovaginal Fistulas. Campion Press, Edinburgh

12. Browning A (2006) A new technique for the surgical management of urinary incontinence after obstetric fistula repair. BJOG 113(4):475-478

13. Goh JT, Krause H, Tessema AB, Abraha G (2013) Urinary symptoms and urodynamics following obstetric genitourinary fistula repair. Int Urogynecol J 24(6):947-951

14. Blaivas JG, Mekel G (2014) Management of urinary fistulas due to midurethral sling surgery. J Urol 192(4):1137-1142

15. Smith ARB, Daneshgari F, Dmochowski R et al (2005) Surgery for urinary incontinence in women. In: Abrams P, Cardozo L, Khoury S et al (eds) 3rd international consultation on incontinence. Health Publications Ltd., Paris, p 1297

16. Carey MP, Goh JT, Fynes MM, Murray CJ (2002) Stress urinary incontinence after delayed primary closure of genitourinary fistula: a technique for surgical management. Am J Obstet Gynecol 186:948-953

17. Taafesse B, Aberha G (2008) Experience of retropubic urethrolysis and sling operation for the treatment of post fistula repair residual incontinence at the Addis Ababa Fistula Hospital, Addis Ababa Ethiopia. Ethiop Med J 46(1):29-35

18. Ascher-Walsh CJ, Capes TL, Lo Y, Idrissa A, Wilkinson J, Echols K, Crawford B, Genadry R (2010) Sling procedures after repair of obstetric vesicovaginal fistula in Niamey, Niger. Int Urogynecol J 21(11):1385-1390

19. Hamlin $\mathrm{RH}$, Nicholson EC (1969) Reconstruction of urethra totally destroyed in labour. Br Med J 2(5650):147-150

\section{Publisher's Note}

Springer Nature remains neutral with regard to jurisdictional claims in published maps and institutional affiliations.

\section{Submit your manuscript to a SpringerOpen ${ }^{\circ}$ journal and benefit from:}

- Convenient online submission

- Rigorous peer review

- Open access: articles freely available online

- High visibility within the field

- Retaining the copyright to your article

Submit your next manuscript at $\boldsymbol{\nabla}$ springeropen.com 